\title{
Motor-In-The-Loop Approach in the Validation of an Induction Machine Model - Online Rotor Resistance Estimation
}

\author{
Tamás Égető ${ }^{1}$, Dr. Károly Veszprémi ${ }^{2}$ \\ 1,2Budapest University of Technology and Economics, HU-1111 Budapest Mügyetem rkp. 3
}

\begin{abstract}
In The article introduces a new motor-in-the-loop (MotIL) concept as a new system level test method for variable frequency drives. The main idea of this methodology is to use a slip ring motor to investigate the effect of the drive system on a real motor. Because of the slip ring structure, the rotor side signals and parameters can be directly observed online as well as offline. Therefore, it can be a good extension of the HIL and PHIL solutions. Compared with HIL and PHIL methodology the MotIL makes it possible to observe the drive system behavior in real physical environment including noises, coupling, nonlinearity and other potentially not modeled factors.

A case study related to rotor resistance estimation is also presented aiming to prove the performance of the MotIL concept. The presented MotIL algorithm focuses on the accurate and robust rotor flux calculation and online rotor resistance measurement. The concept of the introduced algorithm is based on collaboration and self-adaptation of two independent rotor flux estimator.
\end{abstract}

Keywords: Rotor Resistance, Estimation, HIL, FOC

\section{INTRODUCTION}

The usage of induction machines in applications where high torque accuracy and dynamic behavior are critical typically requires the field oriented control (FOC) [1], [2].

The hardware-in-the-loop (HIL) and power HIL (PHIL) solutions [3], [4], [5] make it possible to test the FOC based motor controller in its real embedded and power circuit thanks to the fact that they can emulate effect of the load. The HIL makes possible to test the electronic control unit (ECU) by means of the real time model of the power parts and sensor system. The test of integrated power system's behavior is possible with the PHIL. The efficacy of these verification concept strongly depends on the real time plant model fidelity in the HIL or PHIL.

To handle the risk related to model fidelity, a physical motor based test framework with high level of observability, accuracy and configurability would be a promising solution. Based on the slip ring induction machine (SRIM) this framework can be easily created, this arrangement would be referred to in this article as motor-in-the-loop (MotIL). The main advantage of MotIL is that the motor behavior is not simulated. An additional benefit is a high-level of observability of the rotor side signals. Therefore, direct validation of the motor model in the FOC controller is also possible. Since MotIL framework cannot be so generic as the PHIL, therefore it is not an alternative solution rather an extension.

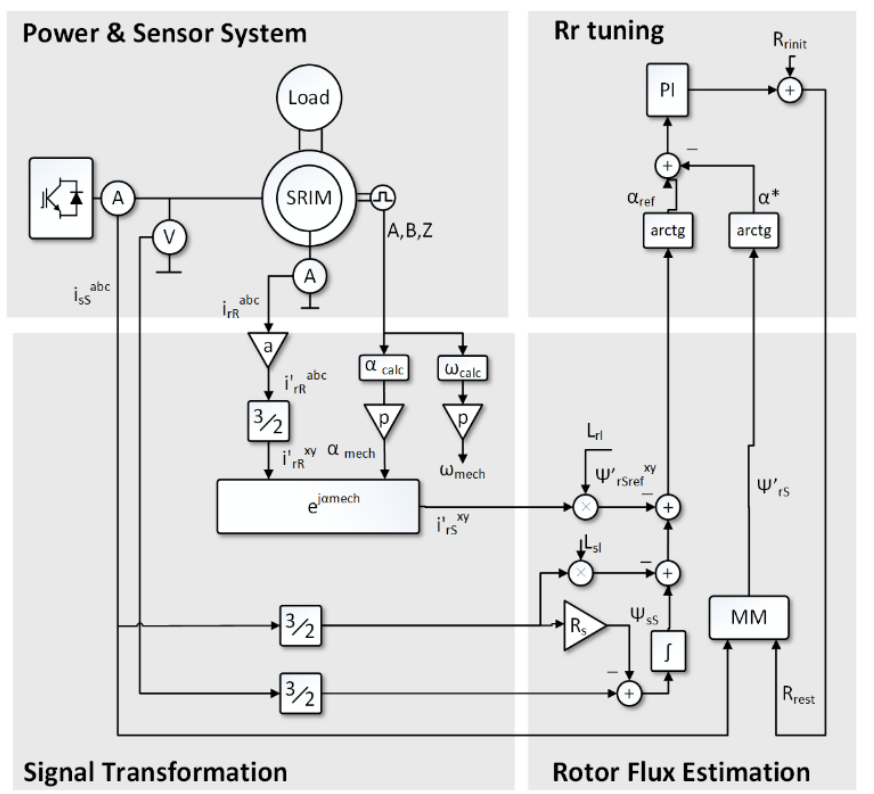

Fig. 1. Signal flow block diagram of the developed algorithm.

The current article introduces a novel approach to validate and monitor FOC based drives. It mainly covers the verification of the accuracy of the motor model since it strongly influences the performance of the motor controller. In order to demonstrate the efficacy of the methodology, online rotor resistance estimation was chosen as a case study.

There are many online and offline solutions for estimating the rotor resistance because of its importance in the FOC. [6] and [7] use the back-EMF for the parameter identification. [8] shows an online solution to estimate the rotor resistance. [9] uses the reactive power for the estimation of the rotor 
resistance. Kalman Filter also can be used to estimate the rotor resistance [10], [11]. [12] shows a method for estimating both the rotor and stator resistances. Compared with recommended MotIL concept, most of these techniques require signal injection by the inverter.

\section{THE DEVELOPED ALGORITHM}

The presented Model Reference Adaptive System based online rotor resistance measurement process uses on two rotor flux $\bar{\Psi}_{r S R e f}^{x y}$ (rotor flux space vector based on rotor current in stator reference frame) and $\bar{\Psi}_{r S}^{\prime}{ }^{x y}$ (rotor flux space vector transformed to stator side in stator reference frame) estimation methods. The first one uses the rotor side measurements so it has no need to use the rotor resistance to calculate rotor flux (Fig. 1). The second one uses the traditional motor model (MM) (Fig. 1) which estimates the rotor flux based on the rotor mechanical speed and stator currents. Since, only the second one uses the rotor resistance during the estimation the error signal can be used as the input for the rotor resistance tuning.

\section{A. Rotor current based rotor flux estimation}

The rotor current measurement in case of a SRIM is possible and this allows the calculation of the rotor flux without the knowledge the rotor resistance. As long as the effect of the saturation can be neglected this calculation will result in a correct rotor flux that can be accepted as a reference. This flux is used to adjust the rotor flux calculated by the machine model.

Equation (1) defines the flux equation of the induction machine in stationary reference frame:

$$
\bar{\Psi}_{r S}^{\prime}{ }^{x y}=\bar{\Psi}_{s S}{ }^{x y}-\bar{\Psi}_{s l S}{ }^{x y}+\bar{\Psi}_{r l S}^{\prime}{ }^{x y}
$$

where

$$
\begin{gathered}
\bar{\Psi}_{s S}{ }^{x y}=\int\left(\bar{U}_{s S}-\bar{\imath}_{s S}^{x y} R_{S}\right) d t \\
\bar{\Psi}_{s l s}{ }^{x y}=\bar{\imath}_{s S}^{x y} L_{s l} \\
\bar{\Psi}^{\prime}{ }_{r l s}^{x y}=\bar{\imath}_{r S}^{\prime x y} L_{r l}
\end{gathered}
$$

The current sensors in the rotor circuit measure the rotor current in the rotor oriented frame $\left(i_{r R}^{x y}\right)$, the measured current should be transformed into the stationary frame $\left(\vec{\imath}_{r S}^{x y}\right)$, so this should be also considered during the transformation apart from the turn ratio $\left(\mathrm{a}_{\mathrm{N}}\right)$ of the machine. Transformation is based on the rotor angle and written in (5):

$$
{\overrightarrow{\iota^{\prime}}}_{r S}^{x y}=a_{N} i_{r R}^{x y} e^{j \alpha_{r m e c h}}
$$

The stator resistance, stator leakage inductance and rotor leakage inductance are considered to be known.

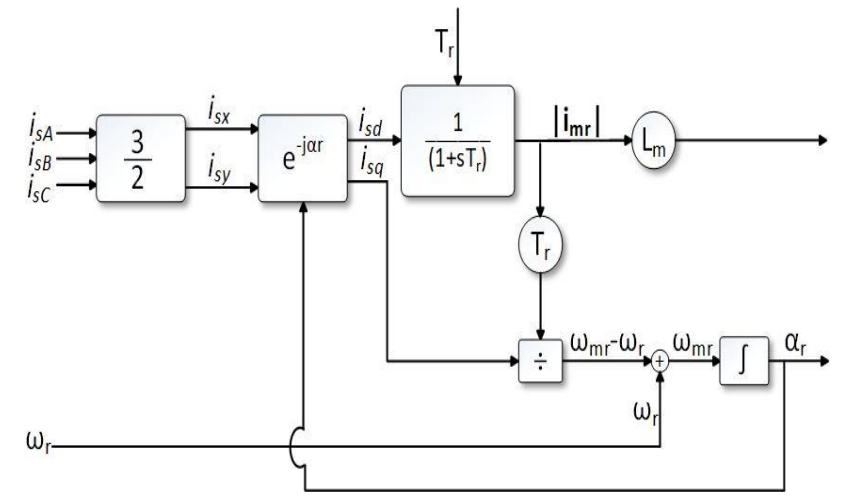

Fig. 2 Closed-loop induction machine motor model [13], where " $r$ " index refers to rotor, "mr" index refers to magnetic field

\section{B. Traditional Rotor Flux Estimation}

Equation (6) is the rotor voltage equation in the rotor flux oriented reference frame:

$$
0=R_{r} \bar{l}_{r \Psi r}+\frac{d\left|\bar{\Psi}_{r \Psi r}\right|}{d t}+j\left(\omega_{m r}-\omega_{r}\right)\left|\bar{\Psi}_{r \Psi r}\right|
$$

Knowing that the rotor flux space vector in rotor reference frame is:

$$
\begin{gathered}
\left|\bar{\Psi}_{r \Psi r}\right|=L_{m}\left|\bar{\imath}_{m \Psi r}\right| \\
\bar{\iota}_{r \Psi r}=\frac{\left|\bar{\imath}_{m \Psi r}\right|-\bar{\imath}_{s \Psi r}}{1+\frac{L_{r l}}{L_{m}}}
\end{gathered}
$$

If we substitute (7), (8) into (6) and use $T_{r}=\frac{L_{r}}{R_{r}}$

$T_{r} \frac{d\left|\bar{\imath}_{m \Psi r}\right|}{d t}+\left|\bar{l}_{m \Psi r}\right|=\bar{\iota}_{s \Psi r}-j\left(\omega_{m r}-\omega_{r}\right) T_{r}\left|\bar{l}_{m \Psi r}\right|$

As we solve the (9) we get the result for the components:

$$
\begin{gathered}
T_{r} \frac{d\left|\bar{l}_{m \Psi r}\right|}{d t}+\left|\bar{\imath}_{m \Psi r}\right|=\bar{\imath}_{s d} \\
\omega_{\text {slip }}=\omega_{m r}-\omega_{r}=+\frac{i_{s q}}{T_{r}\left|\bar{l}_{m \Psi r}\right|}
\end{gathered}
$$

\section{Rotor Resistance Tuning}

Considering two different given cases either $\Psi_{\text {rSRef }}^{\prime x y}$ is leading to $\Psi_{r S}^{\prime x y}$ or $\Psi_{r S R e f}^{\prime x y}$ is lagging to $\Psi_{r S}^{\prime x y}$ it is possible to create a controller which is suitable to adjust the resistance used in the machine model. The difference of two calculated flux vectors is caused by the deviation between the real and estimated rotor resistance.

- $\quad$ if the estimated rotor resistance is higher than the real value the angle between the reference and estimated rotor flux is negative. It is a consequence of the fact that it can be considered as if the slip was reduced so the angle between the stator and rotor flux would be increased.

- the case when the angle between the reference and estimated rotor flux is positive can be considered as a complement of the previous case. 


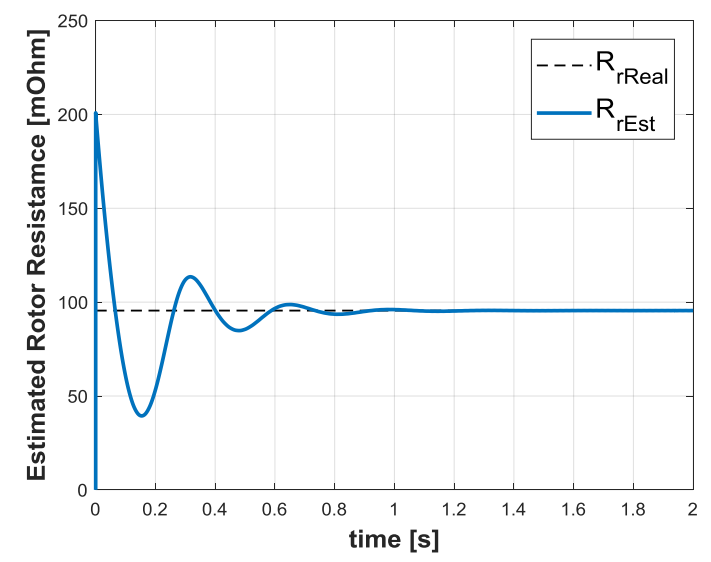

Fig. 3 Estimated rotor resistance

A PI controller is used in the algorithm to get the correct estimated value of the rotor resistance $\left(R_{\text {rest }}\right)$ which is written into the machine model according to following.

- PI controller should increase the Rrest if the $\alpha_{R e f}-\alpha_{r}^{*}$ angle error is positive.

- PI controller should reduce the Rrest if the $\alpha_{R e f}-$ $\alpha_{r}^{*}$ angle error is negative.

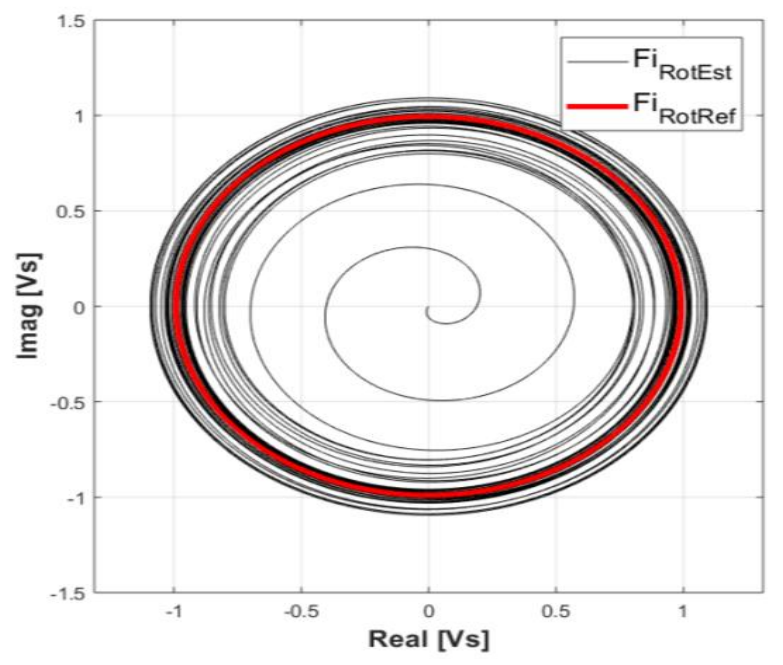

Fig 4. Park vector path of Rotor and Stator flux

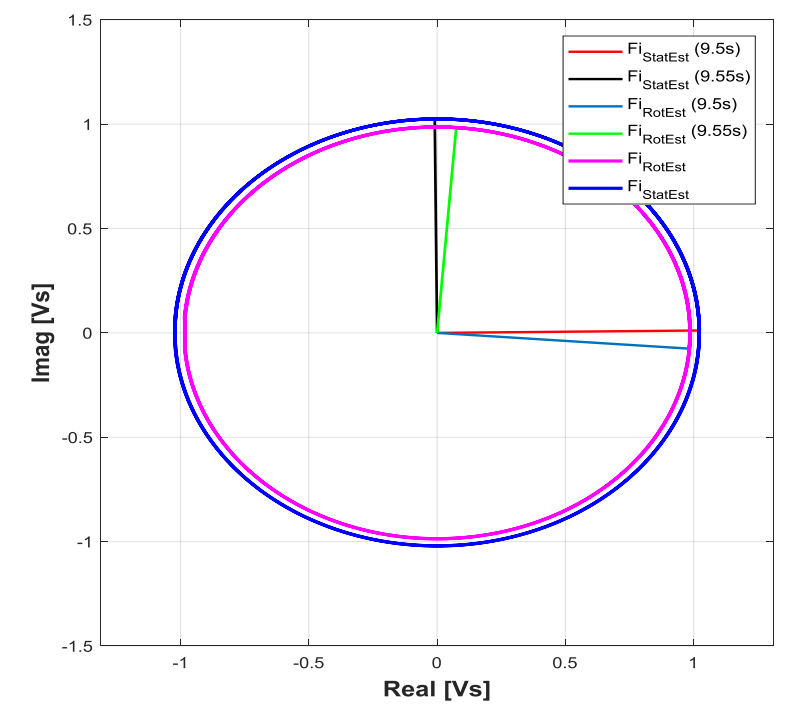

Fig. 5 Park vector of Rotor and Stator flux at two different time.

\section{SIMULATION AND SIGNAL POST-PROCESSING}

The simulation aimed to emulate a motor test bench on which the measurement was done. The power circuit model is based on the SimPower System Toolbox and signal pre-processing is done by standard Simulink blocks.

The SRIM test bench with $55 \mathrm{~kW}$ shaft power was chosen as a subject of the simulation. Previously, the motor parameters were identified by the traditional blocked-rotor and open-circuit measurement. The SimPower system model was parametrized by these parameters except for the iron loss resistance which was neglected.

$$
\begin{gathered}
R_{S}=32 \mathrm{~m} \Omega R_{R}=95.5 \mathrm{~m} \Omega L_{s l}=340 u H L_{r l}=340 \mathrm{uH} \\
L_{m}=12.3 \mathrm{mH}
\end{gathered}
$$

To verify the robustness of the algorithm, the initial value of the rotor resistance is set to $50 \%$ of the real value. Despite a huge error in the initial value of the rotor resistance $(50 \%)$ the algorithm finds the right resistance value of the tested machine.

In Fig. 3 the transient of the rotor resistance can be seen. It resulted in the motor model transient because of the zero initial conditions and the transient of the PI controller in the rotor resistance estimator loop. The track of the rotor flux Park vector can be seen in Fig. 4 and Fig. 5. It can be seen that the machine model is demagnetized at the beginning so the magnitude of the flux is initially zero.

\section{CONCLUSION}

The article introduced the MotIL approach to help motor control developers with verification. MotIL, HIL and PHIL solutions can be integrated into one developing workflow in which the MotIL is the physical platform of the system verification including all relevant physical effects. The MotIL can help the real time model development for the HIL and PHILs. A rotor resistance monitoring algorithm was introduced as a MotIL case study. Thanks to the recommended monitoring method, the test bench operation can be monitored externally without injection of the sensing signals. Finally, the performance of the recommended solution is verified by the Matlab based simulation.

\section{ACKNOWLEDGEMENT}

This work was performed in the frame of FIEK 16-1-2016-0007 project, implemented with the support provided from the National Research Development and Innovation Fund of Hungary, financed under the FIEK 16 funding scheme.

\section{REFERENCES}

1. B. Robyns, P.A. Sente, H. A. Buyse, "Influence of digital current control strategy on the sensitivity to electrical parameter uncertainties of induction motor indirect field-oriented control", IEEE Transactions on Power Electronics, vol 14, no 4, pp 690 - 699, Jul 1999

2. A. Del, Pizzo, E. Pagano, A. Perfetto, "Comparative analysis and parameter sensitivity of field oriented 
"Motor-In-The-Loop Approach in the Validation of an Induction Machine Model - Online Rotor Resistance Estimation"

speed controlled asynchronous motors", Electrical Machines and Drives, 1989. Fourth International Conference on, Sept 1989

3. A. Mohammedi, N. Kabache, S. Moulahoum, "FPGA hardware in the loop validation of direct torque control for induction motor", Methods and Models in Automation and Robotics (MMAR), 2015 20th International Conference on, Aug 2015

4. K. Algarny, A. S. Abdelrahman, M. Youssef, "A novel platform for power train model of electric cars with experimental validation using real-time hardware in-the-loop (HIL): A case study of GM Chevrolet Volt 2nd generation", Applied Power Electronics Conference and Exposition (APEC), 2018 IEEE, March 2018

5. J. Chalupe, R. Grepl, V. Sova, "Design of configurable DC motor power-hardware-in-the-loop emulator for electronic-control-unit testing", Automation and Computing (ICAC), 2015 21st International Conference on, Sept 2015

6. F. Z. Peng, and T. Fukao, "Robust speed identification for speed sensorless vector control of induction motors", IEEE Transactions on Industry Applications, vol. 30, no. 5,pp. 1234-1240, 1994.

7. M. Rashed, and A.F. Stronach, "A stable back-emf MRAS based sensorless low speed Induction motor drive insensitive to stator resistance variation", IEEE Proceeding of Electric Power Applications, vol. 151, no. 6, pp. 685-693, 2004.
8. M.S. Nait Said, and M.E.H. Benbouzid, "Induction motors direct field oriented control with robust on -line tuning of rotor resistance", IEEE Transactions on Energy Conversion, vol. 14, no. 4, pp. 1038-1042, 1999

9. S. Maiti, C. Chakraborty, Y. Hori, and M.C. Ta, "Model reference adaptive controller-based rotor resistance and speed estimation techniques for vector controlled induction motor drive utilizing reactive power", IEEE Transactions on industrial Electronics, vol. 55, no. 2, pp. 594-601, 2008.

10. Jakub Talla, Zdenek Peroutka, Vojtech Blahnik, Lubos Streit, "Rotor and Stator Resistance Estimation of Induction Motor Based on Augmented EKF", IEEE International Conference on Applied Electronics

11. Sarathbabu Duvvuri, Lakshman Kumar Dangeti, Durga Prasad Garapati, Hepsiba Meesala: "State estimation for wound rotor induction motor using discrete-time extended Kalman filter", IEEE International Conference on Power, 18-20 Jan. 2018., Thrissur, India

12. Ahmed G. Mahmoud A. Aziz, Ahmed A. Zaki Diab, Montaser Abd El Sattar, "Speed Sensorless Vector Controlled Industion Motor Drive Based Stator and Rotor Resistances Estimation Taking Core Losses into Account, Nineteenth International Middle East Power Systems Conference (MEPCON), 19-21 Dec. 2017

13. P. Vas, "Sensorless Vector and Direct Torque Control", ISBN-10: 0198564651, 1998 